\title{
Sub-ns-pulsed laser cleaning of an archaeological bone from the Sierra de Atapuerca, Spain: a case study
}

\author{
Md. Ashiqur Rahman ${ }^{1,3,6}$ (D) German F. de la Fuente ${ }^{1}$. José Miguel Carretero ${ }^{2}$. Evan Maina Maingi ${ }^{1,3,5}$. \\ $M^{\text {a Pilar Alonso Abad }}{ }^{3} \cdot$ Rodrigo Alonso Alcalde $^{4} \cdot$ Rémy Chapoulie $^{5} \cdot$ Nick Schiavon $^{6} \cdot$ Luis A. Angurel $^{1}$
}

Received: 10 March 2021 / Accepted: 27 October 2021

Published online: 13 November 2021

(c) The Author(s) 2021 OPEN

\begin{abstract}
Controlled laser irradiation parameters using recently developed sub-nanosecond pulsed laser technology with emission wavelength in the near Infrared regime $(1064 \mathrm{~nm})$ have been assessed on a Pleistocene bone from the archaeological site of Sierra de Atapuerca, Spain. Burst pulse mode was employed to explore contaminant removal efficiency, while at the same time, assessing the degree of damage produced to the underlying original substrate surface. The surface morphology and composition of the deteriorated bone have been characterized, along with the effects of laser irradiation at $1064 \mathrm{~nm}$, using Optical Microscopy (OM), Scanning Electron Microscopy-with Energy Dispersive X-ray Spectrometry (SEM-EDS), and X-ray Photoelectron Spectroscopy (XPS). The most effective laser cleaning parameters in burst mode have been identified in order to optimize the emission parameters of the laser, thus localizing its interaction within the outermost layers of contaminants and degradation products, avoiding damage to the underlying original bone surface. Hence, threshold cleaning and substrate damage values have been determined for this new sub-ns laser, paving the way to safer laser cleaning procedures that may be useful for the effective conservation of bone archaeological artifacts.
\end{abstract}

Keywords Sub-ns laser $\cdot$ Cleaning $\cdot$ Archaeological bone $\cdot$ Sierra de Atapuerca $\cdot$ Cultural Heritage

\section{Introduction}

The Sierra de Atapuerca mountain range has become one of the most famous archaeological regions of the world following the discovery of the 'first hominin' presence in Europe [1, 2]. From a geomorphological point of view, it is a rather complex site characterized by the presence of numerous limestone caves and located in an ancient karstic area of northern Spain, $12 \mathrm{~km}$ east of the city of
Burgos. The plentiful bones and stone tools of Europe's oldest hominins excavated there date back to $0.78 \sim 1.2$ million years [3]. Geologically, Sierra de Atapuerca belongs to the Iberian Mountain Range, with Quaternary deposits mostly found in valleys, fluvial terraces, floodplains, alluvial fans, and colluvial deposits [4]. One of the most surprising discoveries at Sierra de Atapuerca is a cavern site named Sima de los Huesos (the Bones Pit). The pit contained the remains of approx. 166 cave bears from the Middle

$\triangle$ German F. de la Fuente, german.delafuente.leis@csic.es $\mid{ }^{1}$ Instituto de Nanociencia y Materiales de Aragón (CSIC - University of Zaragoza), c/María de Luna 3, 50018 Zaragoza, Spain. ${ }^{2}$ Laboratorio de Evolución Humana and Unidad Asociada de I+D+i al CSIC "Vidrio y Materiales del Patrimonio Cultural (VIMPAC)", Departamento de Historia, Geografía y Comunicación, Universidad de Burgos, Plaza Misael Bañuelos S/N, 09001 Burgos, Spain. ${ }^{3}$ Área de Historia del Arte and Unidad Asociada de I+D+i al CSIC "Vidrio y Materiales del Patrimonio Cultural (VIMPAC)", Departamento de Historia, Geografía y Comunicación, Universidad de Burgos, Po Comendadores S/N, 09001 Burgos, Spain. ${ }^{4}$ Área de Didáctica y Dinamización, Museo de la Evolución Humana, Paseo Sierra de Atapuerca no 2, 09002 Burgos, Spain. IRAMAT-CRP2A Laboratory UMR5060 CNRS, Bordeaux Montaigne University, Pessac, France. ${ }^{6}$ HERCULES Laboratory, University of Évora, Largo Marquês de Marialva 8, 7000-809 Évora, Portugal.

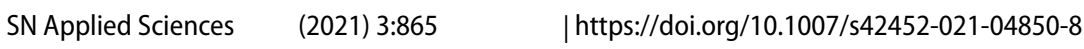


Pleistocene and approx. 28 individual humans with a total of more than 6500 human bone fragments and more than 500 teeth recovered, making this pit one of the biggest collections of earliest hominid fossil remains in the world. Dating analysis suggests the age of the site ranges from at least 0.3 to 0.6 million years $[5,6]$.

Bone degradation processes are referred to as bone diagenesis [7]. Bones are mainly composed of organic molecules (i.e. proteins and fats) and inorganic minerals. They are the compound tissue that is made up of three main parts: (a) mineral that comprises hydroxyapatite $\mathrm{Ca}_{10}\left(\mathrm{PO}_{4}\right)_{6}(\mathrm{OH})_{2}$, (b) protein that mainly comprises collagen, and (c) ground substance (an amorphous gel-like substance in the tissue) which is made of other organic compounds $[8,9]$. After demise, most of the organic collagen is eventually metabolized by the action of bacterial enzymes, which is the first step of bone diagenesis. Bacterial enzymes break down the organic collagen into peptides, and these peptides are reduced to their elemental amino acids, which are normally leached away by the groundwater. As soon as the organic collagen has been removed from bone, the precipitated crystalline hydroxyapatite starts to be degraded by the inorganic weathering processes, with leaching of ions such as calcium $(\mathrm{Ca})$, iron $(\mathrm{Fe})$, aluminium $(\mathrm{Al})$, potassium $(\mathrm{K})$ and manganese $(\mathrm{Mn})$. The collagen and hydroxyapatite are bound together by strong protein-mineral bonds, providing the bones with their strength and durability which will gradually be conceded and lead to a general deteriorated structure. Continuous deterioration will subsequently take place, until full physical breakdown, decalcification, and bone dissolution occur [10]. Additionally, burial soils contain mostly insoluble inorganic phosphorus (P) complexes [11], frequently with $\mathrm{Fe}, \mathrm{Ca}$, and $\mathrm{Al}$. Thus, limited phosphorus leaching is expected, although it relies on the hydrogeology of the buried archaeological soils $[12,13]$, as well as soil microorganisms (like Penicillium) to solubilize insoluble inorganic complexes [11]. On an interment level, the bone is outlined with black stains by the phenomenon of burial silhouette, which has an intriguing link with evidence of burial hydrogeology settings. It has been noted that in sandy and gravelly acidic soils, the organic phosphorus complexes attract other soil metals, most notably manganese, resulting in black stains on the bone surfaces [14].

The most noteworthy point is the degree of bone degradation which is highly dependent on its surrounding environment. In the presence of soil, bone contamination is usually influenced by both physical (such as water, moisture, relative humidity, temperature, soil type, and $\mathrm{pH}$ ), as well as biotic agents (i.e. fauna and flora) $[15,16]$. Water infiltrating down on the nearby environment of bone, normally through the soil above, causes dissolution of its mineral content and leaching out of the bone. In general, the minerals that precipitate are iron and manganese oxides and hydroxides, as well as carbonates (including calcite) and silica. Bone mineralization within the soil results in the gradual addition of inorganic minerals dissolved in groundwater. With time, the diagenetic processes cause the bones to increasingly harden towards a rock-like object. In exceptionally rare cases, soft tissues of bones can also become mineralized [8] [17].

The conservation of archaeological materials and museum stored objects have, during the last decades, been considered a significant challenge for innovative science and multidisciplinary research development. In this sense, modern intervention tools and characterization methods may play an essential role in successfully solving many conservation challenges presently faced by the cultural heritage conservation and restoration community $[18,19]$. Conventional conservation techniques for Cultural Heritage $(\mathrm{CH})$ materials usually include chemical and mechanical cleaning methods that have been employed for centuries. In contrast, laser cleaning techniques may be included as an outstanding and encouraging example of how relatively recent technological advances may be applied to improve conservation methods for $\mathrm{CH}$ materials [20-22].

Although laser cleaning in the conservation of $\mathrm{CH}$ materials began in the early 1970 s $[23,24]$, it took several decades for its wide use due to severe technological limitations. The first laser system used for conservation operated with Ruby and Nd: YAG lasers, with a low pulse repetition rate, a lack of flexible beam distribution mechanisms, very poor consistency for long-term operations, and high experimental costs $[25,26]$. The technical development for 
laser cleaning improved dramatically later in the 1980s, but the experimental costs were still out of proportion for use in the $\mathrm{CH}$ sector. It was a crucial period for the novel approach of laser conservation to survive with relatively low productivity when compared to traditional mechanical and chemical cleaning techniques [27]. The availability of new laser technologies enabled systematic investigations on extensive applications after the 1990s, triggering dissemination of the laser methodology in $\mathrm{CH}$ conservation practise $[28,29]$.

The laser cleaning approach has been successfully applied for almost three decades, however, on a variety of archaeological materials with diverse types of contamination and/or deterioration. Laser cleaning of archaeological mineralized bone has not gained much attention yet from the conservation and restoration community, as very few case studies have been reported so far [30-32]. The main reason behind this may be related to the absence of adequate pulse lasers which may avoid damage to sensitive/ fragile surfaces. Bones are neither uniform in their composition nor the deterioration and mineralization occurring in bones are homogeneous. Furthermore, reducing the risk of damage to the original bone substrate surface appears as a crucial challenge. To solve the latter, it will be necessary to establish which parameters lead to a distinct laser interaction with the contaminant layers versus the original bone substrate surface.

Thus, if properly applied, laser cleaning of bone can minimize and avoid both mechanical and chemical disruption of historic patinas, while selectively eliminating contaminating agents (i.e. unwanted fossilized minerals, soil, etc.) in archaeological bones. The traditional cleaning method applied on an excavated bone is mostly based on the use of a neutral detergent wash under controlled temperature, or the application of alcohol or other chemical solvents that so often alter the bone surface. In contrast, laser cleaning is a dry method where bone parts with rough surfaces and weakened regions can be, in principle, cleaned without altering their original surfaces.

In essence, archaeological bones are quite vulnerable to contaminants. They get discoloured over the years due to inorganic mineralization weathering and may appear dusty (exposed up with encrustations, blackish contaminants, and dust), thus losing their original appearance and aesthetic value. The objective of the present work is to make use of new sub-nanosecond (sub-ns) pulsed laser technology [33] to ascertain its potential use in removing contaminants from Pleistocene bone sample surfaces found in Sierra de Atapuerca while respecting the original patina on the substrate surface to preserve as best as possible the surface anatomical details obscured by contamination. The reason for using a sub-ns laser is to avoid excessive heating of the irradiated substrate. On the one hand, this laser is compact and air-cooled and offers several advantages with respect to the substantially more expensive femtosecond ( $\mathrm{fs}$ ) lasers. On the other, it is expected to significantly reduce thermal incubation [34-37] with respect to competing ns pulsed lasers, most commonly employed for surface cleaning.

\section{Materials and methods}

\subsection{Materials}

One Pleistocene bear bone from Sima de los Huesos was selected for the present study. It is described physically as a $6.3 \mathrm{~cm}$ long $\times 0.9-1.2 \mathrm{~cm}$ wide $\times 0.35-0.7 \mathrm{~cm}$ thick rib sample excavated in 1986 as soiled material, dating back to 430,000 years. Some part of this bone exhibits various shades of greyish discoloration different from the natural whitish-yellowish colour typical with fossilized bones, presumably due to Fe staining. It was inhomogeneously covered with hard blackish encrustations, greyish contaminants, and atmospheric soil dust, as well as with weathering patterns suggested to be caused by manganese $(\mathrm{Mn})$ mineralization effects [14, 38-40]. Dust on the bone surface was previously removed by a standard mechanical procedure; front and side-view photographs of the bone sample are shown in Fig. 1. A particular objective of this study is to remove this bone's hard-blackish stains from its outmost layer without altering its original surface. 
Fig. 1 Front (upper photograph) and back surface (lower photograph) views of a bear rib (shaft) bone excavated at the Sima de los Huesos site at Sierra de Atapuerca (Burgos, Spain)
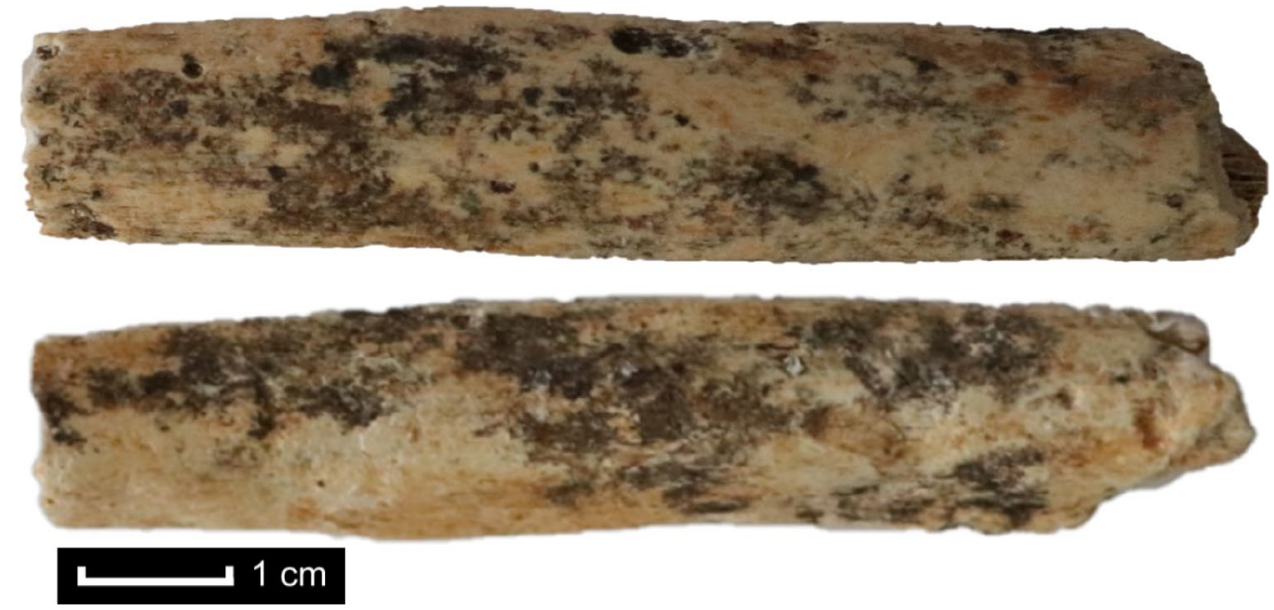

\subsection{Experimental}

\subsubsection{Laser irradiation of Pleistocene bone}

Figure 2 provides an illustration of the laser apparatus used to carry out this study. It also includes a simplified representation of the ideal physical phenomena induced when a laser beam is focussed onto a contaminated surface of an archaeological artifact. The resulting effects are associated with the complex processes described for laser ablation [44], which include plasma formation and consequent shockwaves which help remove the contamination layer away. These complex phenomena are illustrated in the upper centre inset of Fig. 2. For the fixed pulse width laser used in this study, selection of appropriate power output and pulse repetition rate enables contaminant removal while avoiding damage to the patina layer and substrate below it [45]. The relationship between laser intensity and beam energy distribution is represented in the upper right inset of Fig. 2 in order to help visualize how beam waist is defined here. Finally, the lower inset represents the burst pulse mode used in this study, where consecutive groups (bursts) of pulses irradiate the material surface at a given position under specific conditions to avoid causing thermal damage to the substrate, while removing contaminants. It is important to have in mind that the interval between bursts (usually ranging between $100 \mathrm{~ms}$ and $1 \mathrm{~s}$ ) is much longer than the interpulse separation (ca. $2 \mu \mathrm{s}$ ) and the pulse width (800 ps). It allows the irradiated surface to cool sufficiently between burst sequences.

Laser irradiation experiments were performed using a computer-controlled galvanometer-scanner-equipped sub-ns pulsed near Infrared ( $n-I R)$ laser. This was manufactured by Rofin (Munich) and its essential emission characteristics are summarized in Table 1. Most important consideration is given to wavelength $(\lambda)$, pulse width $\left(\tau_{p}\right)$, pulse repetition rate or frequency $\left(f_{p}\right)$, and nominal power $\left(P_{\max }\right)$. The output laser beam follows a circular gaussian energy distribution mode.

A burst pulse mode method (Fig. 2) [46], provided by the computer CAD-like software controlling the laser output and integrated galvanometer mirror scanner head, was used to selectively irradiate the samples' surface around specific localized areas. In burst mode, the laser performs a spot-by-spot scanning process, where the scanning parameters can be adjusted. A laser system configured to operate in burst mode generates a burst (i.e. a sequence of a defined number of pulses) with a high intra-burst repetition rate in each preselected position on the sample surface. A single burst is evident at a particular position, where this specific mode enables irradiation of selected areas controlling the laser emission parameters, the distance between burst positions, the energy of each individual burst pulses, and the number of pulses in a burst repeated over the same irradiated position (Fig. 2, lower inset). The latter exerts control over thermal incubation, that is, accumulation of energy input as a function of time into a given area of the sample. In this laser system, irradiance (average power density of a given laser pulse) [47] and fluence (pulse energy density) values are proportional. In this work, irradiance values have been taken as a basic reference, for direct and accumulated (thermal incubation) damage, since it is independent of different laser devices and emission characteristics (particularly pulse duration). 


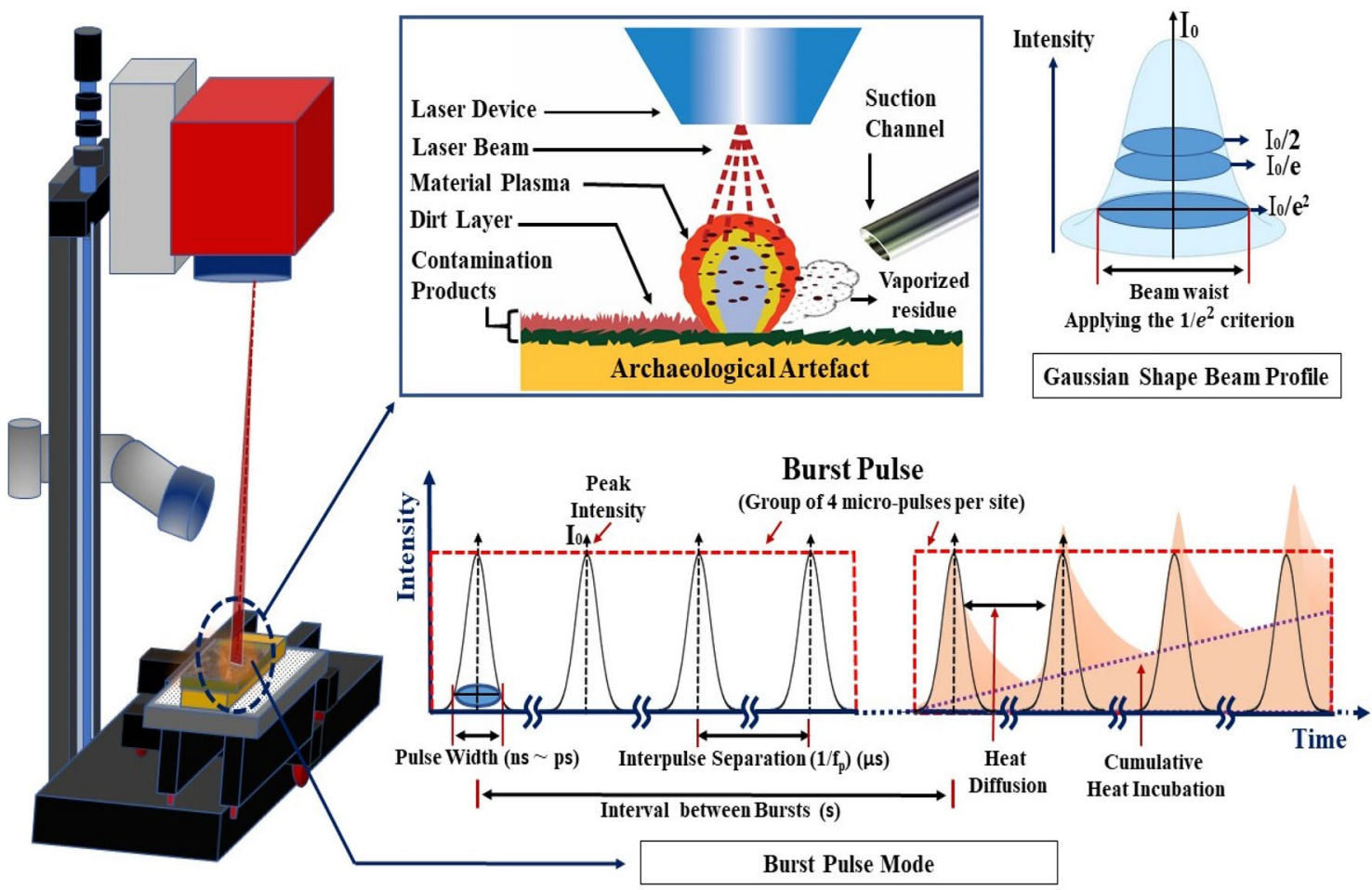

Fig. 2 Illustration of the laser cleaning apparatus used for the present study (left), where the laser $x-y$ scanner head is shown above the archaeological artifact sample and a fume extraction device. The upper centre inset illustrates the ideal sample behaviour under laser irradiation, where the contaminant layer is removed, while the protective patina (green) is preserved. The upper right inset represents the relationship between laser intensity and different definitions of beam waist related to a Gaussian beam profile, highlighting the $1 / \mathrm{e}^{2}$ criterion used in this study [41]. The lower inset

Table 1 Characteristic emission of the sub-ns laser employed for the present study. Values are given for the nominal (maximum) output power $\left(P_{\max }\right)$, emission wavelength $(\lambda)$, pulse width $\left(\tau_{p}\right)$, pulse repetition rate $\left(f_{p}\right)$, and beam waist applying the $1 / e^{2}$ criterion $\left(D_{b}\right)$ for a Gaussian beam distribution (Fig. 2)

\begin{tabular}{llllll}
\hline Laser type & $P_{\max }(\mathrm{W})$ & $\lambda(\mathrm{nm})$ & $\tau_{\mathrm{p}}(\mathrm{ps})$ & $\mathrm{f}_{\mathrm{p}}(\mathrm{kHz})$ & $\mathrm{D}_{\mathrm{b}}(\mu \mathrm{m})$ \\
\hline $\mathrm{n}$-IR & 8 & 1064 & 800 & $200-800$ & 80 \\
\hline
\end{tabular}

\subsubsection{Characterization}

Surface morphology, elemental composition, and microstructure were characterized before and after laser treatment of the samples, both on their surface and cross-section. Environmental Scanning Electron Microscopy (ESEM) (Quanta FEG-250) was used for high-resolution imaging while elemental composition was semi-quantitatively determined by EDS. In addition, high resolution investigation was carried out on polished cross-sections of the bone sample using field-emission SEM (FE-SEM, Carl Zeiss MERLIN) comprising secondary electrons (SE) and in-lens drawings represent the laser intensity output in a given position as a function of time for the burst pulse mode employed to control thermal damage $[42,43]$. The lower inset graphically illustrates the pulse width $\left(\tau_{\mathrm{p}}=800 \mathrm{ps}\right.$ ) and pulse-to-pulse (interpulse) separation (ca. $2 \mu \mathrm{s}$ ) on the left side. On the right side it provides an illustration of how thermal incubation takes place along the consecutive pulse irradiation process. Between bursts, a much larger time interval that depends on the particular geometry selected to make the laser treatment (ca. $0.4 \mathrm{~s}$ ) is indicated

detectors. Chemical composition was semi-quantitatively determined in this case by EDS (INCA350 Oxford Instruments) using an electron acceleration voltage of $15 \mathrm{kV}$.

An X-ray photoelectron spectrometer (Kratos AXIS Supra XPS, monochromatic AI Ka X-ray source with $225 \mathrm{~W}$ : $8 \mathrm{~mA} / 15 \mathrm{kV}$ energy) was used to study the outermost bone surface chemical composition. A base pressure of $\sim 10^{-9} \mathrm{Torr}$ and an area size of $700 \mu \mathrm{m} \times 300 \mu \mathrm{m}$ were used to gather the photoelectron signal for the complete survey spectrum. The pass energy value per step employed was - (i) Wide: $160 \mathrm{eV}$ / 1000 meV and ii) Regions: $20 \mathrm{eV} / 100 \mathrm{meV}$. All samples were investigated by means of a combined electron and argon ion gun neutralizer system $(\mathrm{Ar}+500 \mathrm{eV})$ to diminish sample charging effects. In general, XPS provides information on the atomic concentration of the elements present on the topmost surface of the sample. For this study, XPS characterization was used to quantitatively determine the chemical composition at the surface of the sample. A total of 8 distinct areas of the bone sample were analysed; typical depth of the analysis is about $5 \mathrm{~nm}(3-10 \mathrm{~nm})$. General survey-scan and selected regions of interest spectra were 
collected in Hybrid-slot lens mode, which corresponds to a spot analysis area of approx. $700 \mu \mathrm{m} \times 300 \mu \mathrm{m}$. The sample was analysed "as received" and after $300 \mathrm{~s} \mathrm{Ar}+$ ion etching.

In order to observe the surfaces of bone before and after the laser treatment, a portable microscope (DinoLite Edge) with a maximum magnification capacity of $230 \times$ was employed. It was fitted with an LED lighting accessory and linked via USB cable to a computer using Dino Capture 2.0 operating software.

\section{Results and discussion}

Undesired contaminant removal from the abovedescribed bone surface requires laser emission conditions which may ideally cause a considerable difference in absorption between the contaminants and the bone substrate itself. The most relevant parameters under consideration for this task are summarized in Table 2 . Amongst these, the nominal output power $\left(P_{\text {max }}\right), f_{p}, \tau_{p}$ and $D_{b}$ determine the resultant irradiance $\left(I_{L}\right)$ values; i.e. $I_{L}=\frac{4 P}{\pi f_{p} \tau_{p} D_{b}^{2}}$. On the other hand, thermal incubation is also determined by the above processing parameters but determined directly by the number of incident pulses within a given area of the surface in a given time, combined with the degree of overlap between consecutive pulses [48-50]. A combination of irradiance and incubation values determines the degree of interaction between the laser and the substrate, and thus the degree of damage to the latter [51]. Very small areas were thus irradiated throughout the different regions within the bone surface and initially explored and examined by confocal and electron microscopy, where melting evidence and microstructure changes were properly assessed. Determined cleaning and damage threshold values are based on multiple observations and experiments carried out over representatively different surface finish sites within the bone. From these observations, it was concluded that irradiance levels below $0.20 \mathrm{GW} \mathrm{cm}^{-2}$ guarantee that damage to the bone is avoided. These also suggested that damage to the substrate surface was produced at an irradiance value of 0.22 $\mathrm{GW} \mathrm{cm}{ }^{-2}$. Accordingly, and considering a safety margin, irradiance values below $0.20 \mathrm{GW} \mathrm{cm}^{-2}$ apparently do not cause damage and were thus selected for further cleaning studies. The incubation level was kept constant for all of these initial experiments, as gathered from the number of pulses $\left(\mathrm{N}_{\mathrm{p}}\right)$ applied in burst mode, as specified in Table 2 . Irradiation was focused on the dark contaminated areas of the sample shown in Fig. 1.

A "cleaning" threshold irradiance $I_{L}$ for $n$-IR burst mode irradiation with emission at $1064 \mathrm{~nm}$ was thus determined with the aim of eliminating the dark blackish coloured over-layers from the light whitish coloured substrate. In various areas, multiple laser irradiation treatments were performed on the bone surface, which, in all cases, underwent prior soft brush mechanical cleaning to remove loose dirt. Below this $\mathrm{I}_{\mathrm{L}}$ cleaning threshold value, no contaminant removal was appreciated.

The irradiance values applied for the above experiments thus ranged from $\sim 0.18$ to $\sim 0.6 \mathrm{GW} \mathrm{cm}^{-2}$ by changing the laser system's power output. Further irradiation of selected regions in the bone sample was carried out between the lowest power value of $4.39 \mathrm{~W}$ and $7.24 \mathrm{~W}$, where the highest non-damaging irradiance values were

Table 2 Experimental parameters used for the initial assessment of the laser interaction with archaeological bone studied and reported here

\begin{tabular}{|c|c|c|c|c|c|c|}
\hline Region ID & $\mathrm{P}(\mathrm{W})$ & $f_{p}(k H z)$ & Pulse Energy $(J)$ & $\mathrm{F}_{\mathrm{L}}\left(\mathrm{J} / \mathrm{cm}^{2}\right)$ & $\mathrm{I}_{\mathrm{L}}\left(\mathrm{GW} / \mathrm{cm}^{2}\right)$ & Observations \\
\hline 1 & 7.24 & 300 & $2.41 \times 10^{-5}$ & 0.48 & 0.60 & $\begin{array}{l}\text { Damage due to high incubation, thus melting and cracks gener- } \\
\text { ated on the surface (Fig. } 6: \mathrm{L} \_W \text { ) }\end{array}$ \\
\hline 2 & 6.77 & 500 & $1.35 \times 10^{-5}$ & 0.26 & 0.33 & Damage, thus melting and cracks generated (Fig. 6: L_G) \\
\hline 3 & 6.29 & 600 & $1.05 \times 10^{-5}$ & 0.22 & 0.28 & Damage, thus melting and cracks generated \\
\hline 4 & 5.34 & 600 & $8.9 \times 10^{-6}$ & 0.17 & 0.22 & Damage, thus melting and cracks generated (Fig. 3: g \& h) \\
\hline 5 & 5.34 & 700 & $7.63 \times 10^{-6}$ & 0.15 & 0.19 & $\begin{array}{l}\text { No damage appears, hard blackish encrustations mostly cleaned } \\
\text { (Fig. 3: e \& f, and Fig. 6: G_1) }\end{array}$ \\
\hline 6 & 6.29 & 800 & $7.86 \times 10^{-6}$ & 0.16 & 0.20 & No damage appears, hard blackish encrustations mostly cleaned \\
\hline 7 & 4.39 & 600 & $7.32 \times 10^{-6}$ & 0.14 & 0.18 & No damage appears, hard blackish encrustations mostly cleaned \\
\hline
\end{tabular}

The laser fluence $F_{L}$ is the emitted energy of a given pulse per unit area of spot size, the irradiance $I_{L}$ is the laser fluence per pulse duration, the pulse repetition rate $f_{p}$ is the number of pulses per second, the pulse energy $E_{p}$ is determined by dividing the output power by the pulse repetition rate, and the effective pulse number $N_{p}$ is the number of pulses received in any specific position of the surface in burst mode (fixed at 25). The distance between two positions was fixed at $20 \mu \mathrm{m}$ 
achieved (Table 2: Regions ID- 5,6,7). Several regions were handled, covering $3 \mathrm{~mm}$ square areas each, under the same irradiance conditions while leaving a particular area as the reference for the proper cleaning procedure. It takes approximately $0.95-1.2 \mathrm{~s}$ to clean the $3 \mathrm{~mm}$ square region with typical processing parameters.

Figure 3 presents optical micrographs of the actual area of the bone previously cleaned by conventional mechanical methods. A blackish mineralized region with hard greyish encrustations is also shown, along with laser cleaned regions, all accompanied by the corresponding SEM images for the same areas. As the pulses exhibit a Gaussian spatial beam profile, the maximum, non-damaging laser irradiance $I_{\llcorner}$on the sample surface determined for dark mineralized area contaminant removal is $\sim 0.20 \mathrm{GW}$ $\mathrm{cm}^{-2}$ (Table 2). The dark blackish and greyish contamination crusts often resulted in surface discoloration into a brownish colour, but SEM-EDS and XPS characterization studies suggest that laser cleaning did not cause any compositional changes under these conditions. It is suggested that the thermal dissociation of the $\mathrm{Mn}$ and Fe compounds combined may be the reason for a minimal brownish alteration. Similar results for different area treatment revealed that, at $I_{L}$ values slightly above the ablation threshold, the mineralization is not fully removed and a very thin layer of matrix material can still be present on the mineralized area of the surface (Fig. 3e).

In both mappings and area analysis by SEM-EDS, the laser-cleaned region also suggests the presence of a significant amount of $\mathrm{Mn}$. This is not surprising, in view of previous studies confirming that $\mathrm{Mn}$ may be part of the bone itself [52]. The cross-section of the bone sample was thus studied by FE-SEM to further explore the presence of $\mathrm{Mn}$ and other representative elements within the bone, and to semi-quantitatively determine its chemical composition by EDS (Figs. 4 and 5). Thus, the presence and distribution of $\mathrm{Ca}$ and $\mathrm{P}$, essential components of bone, is confirmed and observed to increase significantly below a depth of ca. $6 \mu \mathrm{m}$. Mn is detected to a depth of ca. $25 \mu \mathrm{m}$ and follows a similar cross-section distribution trend as $\mathrm{Fe}$, thus it is consistent with its incorporation through a mineralization process. In addition, the cross-section elemental analysis map distributions shown in Fig. 5 may be consistent with its possible presence as an original bone component. Furthermore, $\mathrm{Al}$ and Si confirm that the bone has been in contact with clay, as their presence is found significantly reduced below a depth of ca. 8-10 $\mu \mathrm{m}$. These measurements are thus consistent with the essential fact that the presence of contaminants appears restricted to the outermost layers (several $\mu \mathrm{m}$ ) of the bone artifact. On the other hand, the mechanical breakdown or chemical degradation of the bone surface, to the degree that the bone has been buried for a long period, allowed the precipitation of $\mathrm{Mn}$ and $\mathrm{Fe}$ compounds to a visible depth; hence their mineralization produces blackish encrustations and greyish stains on the artifact's outermost layer (Fig. 3c).

XPS analyses were consistent with those obtained by EDS and were used to determine the effect of laser irradiation and damage on elemental composition at the outermost surface. Thus, after a high irradiance treatment which resulted in severe melting of the bone surface (Fig. 6: L_W, L_G; Table 2: Regions ID-1, 2; Table 3: L_W, L_G) the Mn content was observed to increase after surface ion etching, while that of Fe decreased (Table 3:Y_1 vs. G_1). Therefore, while high irradiance level laser treatments showed that the bone samples were fully melted due to the large level of heat accumulation (thermal incubation), it was possible to physically observe the variations in surface aspect as a function of the irradiance. These included drastic changes with respect to the original texture, morphology, and colour of the bone sample (Fig. 6: L_W, L_G; Table 2: Regions ID-1, 2). In addition, Fig. 6: G_1 confirms that $\mathrm{Mn}$ and Fe are still present in appreciable amounts within the greyish area irradiated at $0.19 \mathrm{GW} \mathrm{cm}^{-2}$ (Table 2: Region ID-5; Table 3: G_1).

Table 3 shows the XPS survey and analysis data for the areas specified on the optical micrographs of Fig. 6. Results have been quantified for the detected elements using the C $1 \mathrm{~s}$ binding energy spectrum as reference both, before and after $300 \mathrm{~s}$ of $\mathrm{Ar}+$ ion etching. The $\mathrm{Ca} / \mathrm{P}$ atomic ratio reflects a consistent composition related to the essential Ca hydroxyapatite structure of bone, found to allow for significant compositional variations in archaeological fossilized bones [53-55]. Fluorine may also be expected in fossil bones and has been related particularly with water intake [55], thus it varies depending on the site at which the fossils are found. Elements like $\mathrm{Si}, \mathrm{Al}, \mathrm{S}, \mathrm{Fe}, \mathrm{Mn}, \mathrm{Na}$, and $\mathrm{N}$ may be associated with the burial environment, as they are related to aluminosilicates (such as feldspars, for example), nitrates, sulphates, etc., generally found as components of soil in the Sierra de Atapuerca archaeological site [56]. The several $\mathrm{nm}$ etchings performed for this XPS study suggest that in some of the areas where $\mathrm{Mn}$ is found, its presence increases slightly as the analysis is 


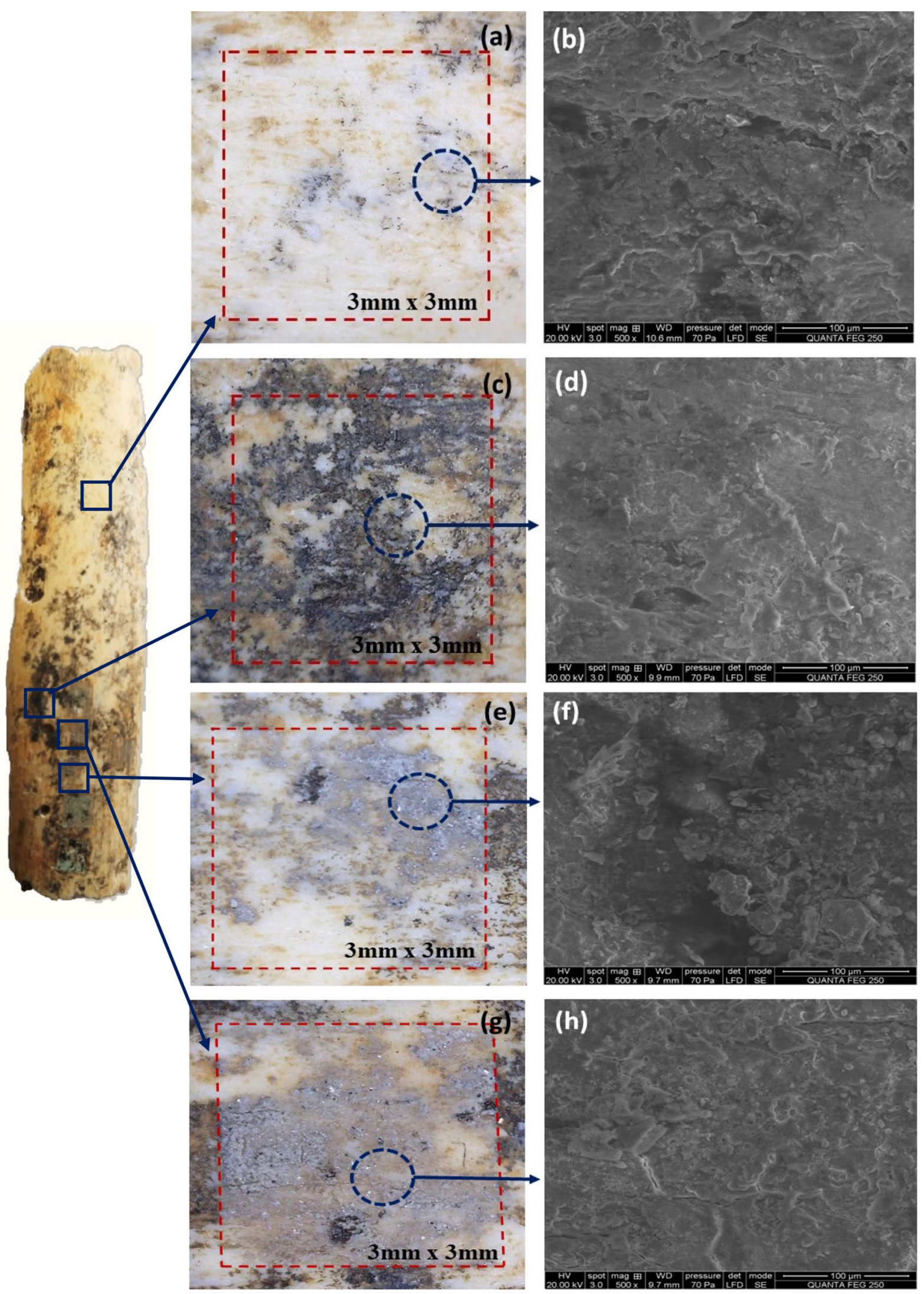


4 Fig. 3 Optical microscopy and SEM images obtained on the Pleistocene bone sample subjected to this study: 'a and b' correspond to the non-treated whitish original surface; 'c and d' to the original $M n$ mineralized blackish dark surface; 'e and $f$ ' to the $n$-IR laser-treated bone surface (Table 2: Region ID-5); ' $g$ and $h$ ' to the laser-treated surface where melting is evident (Table 2: Region ID—4)
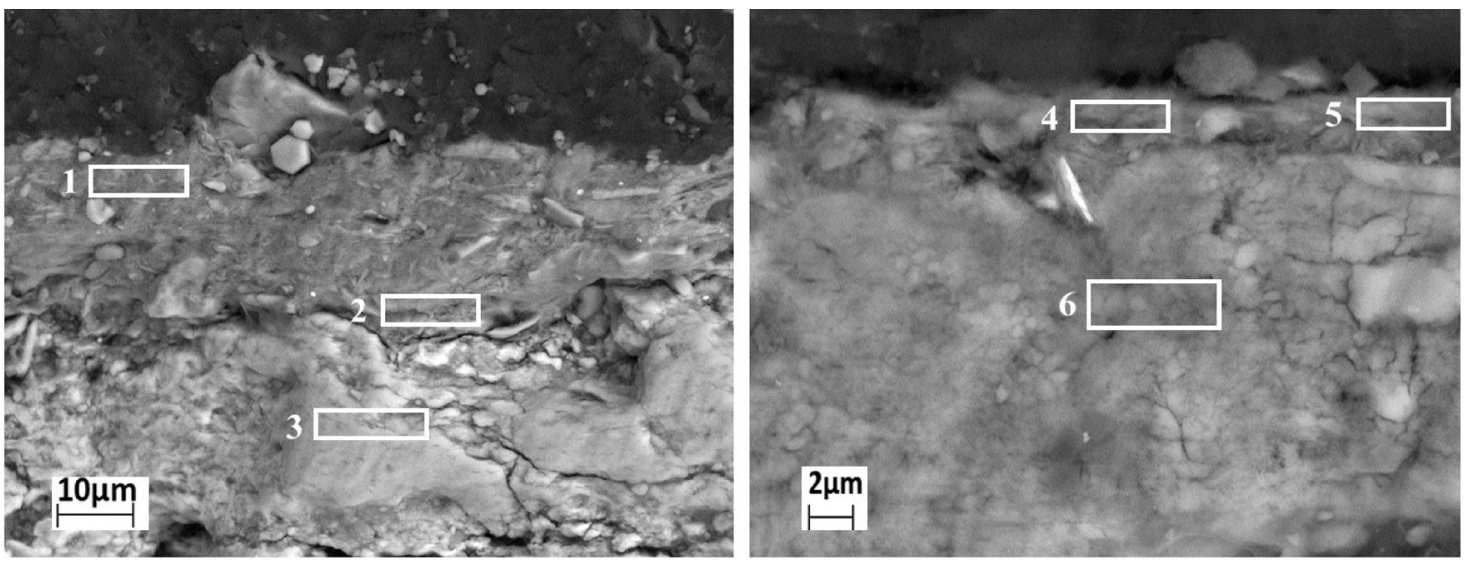

\begin{tabular}{|r|l|l|l|l|l|l|l|l|l|l|l|l|}
\hline $\begin{array}{l}\text { Spectrum } \\
(\% A t)\end{array}$ & O & Ca & Al & Si & P & Mn & Fe & K & Na & Mg & Cl & Total \\
\hline 1 & 56.2 & 8.98 & 8.82 & 14.8 & 4.90 & 0.49 & 2.36 & 1.92 & 0.23 & 0.99 & 0.31 & 100 \\
\hline 2 & 40.4 & 12.3 & 9.54 & 17.3 & 2.89 & 8.12 & 5.95 & 3.51 & -- & -- & -- & 100 \\
\hline 3 & 65.9 & 20.9 & 0.19 & 0.22 & 11.8 & -- & 0.19 & 0.15 & 0.48 & -- & 0.17 & 100 \\
\hline 4 & 63.4 & 3.95 & 8.40 & 14.8 & 2.64 & 2.13 & 2.02 & 1.36 & -- & 0.83 & 0.39 & 100 \\
\hline 5 & 65.3 & 2.00 & 11.07 & 14.4 & 1.42 & 2.10 & 1.21 & 1.49 & -- & 0.73 & 0.30 & 100 \\
\hline 6 & 65.5 & 20.3 & 0.29 & 0.40 & 11.7 & 0.70 & 0.25 & -- & 0.53 & -- & 0.35 & 100 \\
\hline
\end{tabular}

Fig. 4 Non-irradiated bone cross-sections observed on micrographs obtained by FE-SEM under different magnification. EDS analyses performed on the indicated areas are summarized in the table below. The presence and distribution of $\mathrm{Ca}$ and $\mathrm{P}$, essential components of bone, is confirmed and observed to increase signifi- cantly below a depth of ca. $6 \mu \mathrm{m}$. Contaminants are thus restricted to the outermost layers of several $\mu \mathrm{m}$. Mn is detected to a depth of ca. $25 \mu \mathrm{m}$ and follows a similar trend as Fe. Al and Si confirm that the bone has been in contact with clay, as their presence is found significantly reduced below a depth of ca. 8-10 $\mu \mathrm{m}$ 

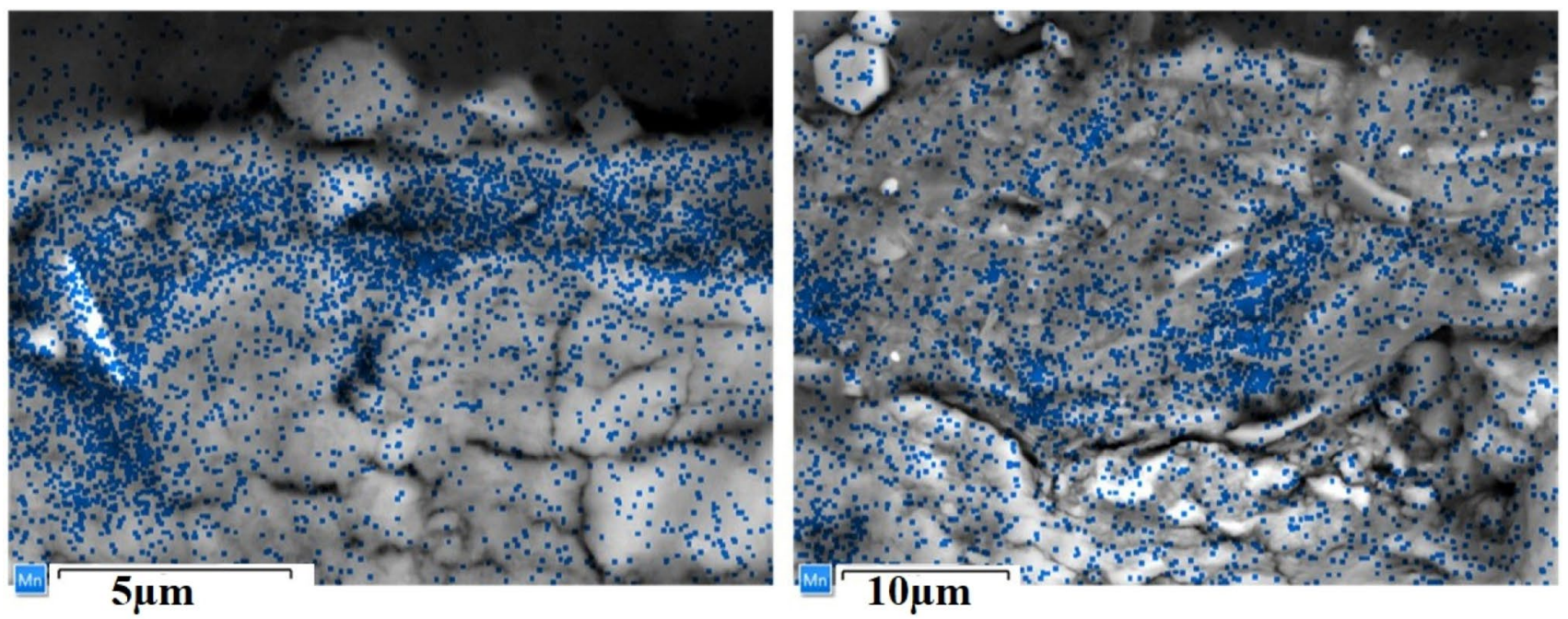

Fig. 5 Non-irradiated bone cross-section observed under FE-SEM and the corresponding EDS map analysis for Mn ( 2 different areas of interest presented)

performed inwards from the outermost surface. This corresponds roughly to less than $10 \mathrm{~nm}$, so it is not representative of the bulk sample. Nevertheless, it is consistent with the presence of contaminants containing $\mathrm{S}$ and $\mathrm{F}$ at the outermost surface of the samples. It is more appropriate here, however, to compare original areas of the bone with those affected by the laser irradiation. This is the case for $Y \_1$ and $G \_1$ areas, whose composition are shown in Table 3. For example, a decrease in $\mathrm{Ca}, \mathrm{Si}, \mathrm{Al}$, and Fe content is accompanied by an increase in $\mathrm{P}$ and $\mathrm{Na}$ upon laser irradiation, consistent with the removal of aluminosilicates and iron-containing compounds expected to be present in the soil found in the site [56]. In addition, the fact that $\mathrm{P}$ and $\mathrm{Na}$ content increases after laser irradiation may be indicative of their stabilization via melting, inevitably causing damage to the surface. This is consistent with the surface aspect observed on samples L_W and L_G in Fig. 6, within the dark area affected by the laser. Furthermore, the dark colour observed in the latter contains Fe and Mn, which are known to exhibit such colour once their compounds have solidified from a melt [57]. Mn signals were also observed by SEM-EDS analysis, as discussed above, and its presence was confirmed at and near the surface of the sample by XPS. It seems thus reasonable to assume that the presence of $\mathrm{Mn}$ may originate not only on mineralization but also on the original bone itself.

Regarding laser irradiation of the archaeological bone sample, this work has established a damage threshold in terms of the irradiance value. There is a need, however, to explore more in detail the relationship between irradiance and thermal incubation, in order to approach future laser conservation work from an optimum understanding of parameters which may assure respectful intervention of these types of artifacts. 


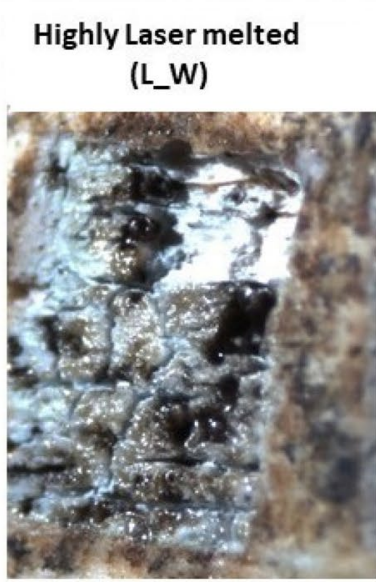

Laser melted

$$
\text { (L_G) }
$$

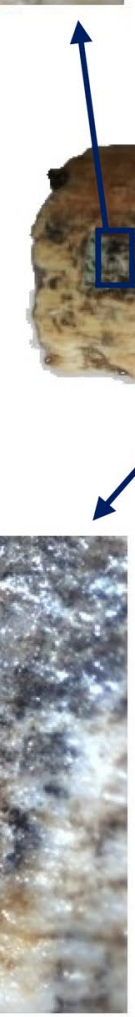

Greyish, Laser treated (G_1)

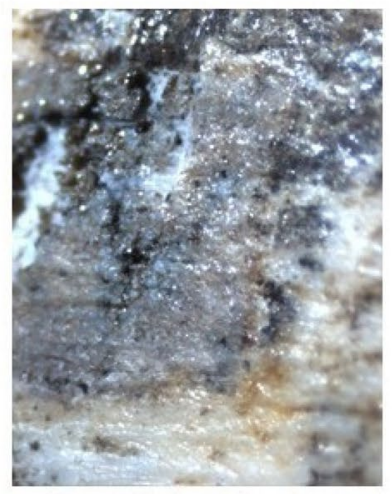

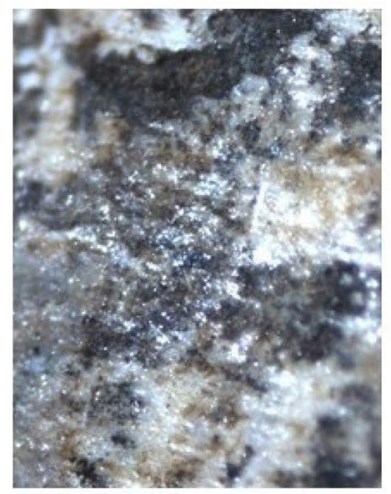

Greyish, Laser treated (G_2)
Yellowish, not treated (Y_1)
Yellowish, not treated (Y_2)
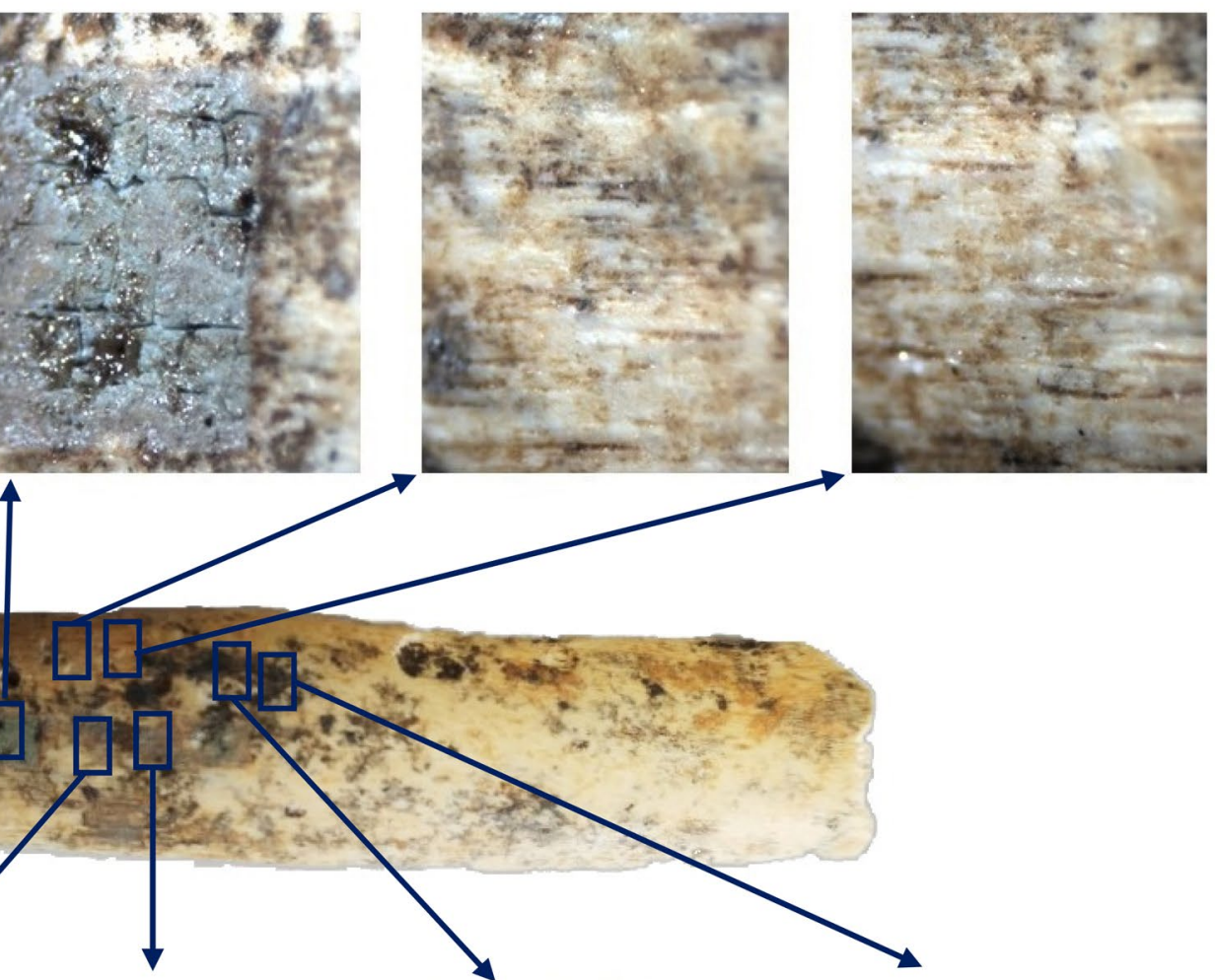

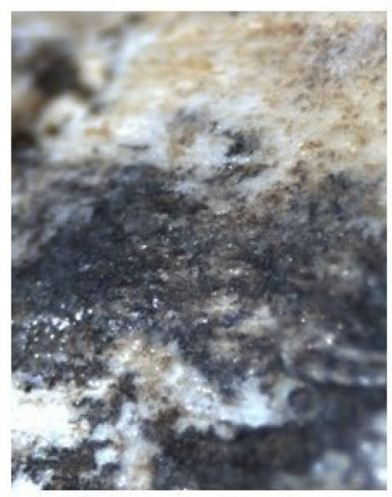

Blackish, not treated

(B_1)

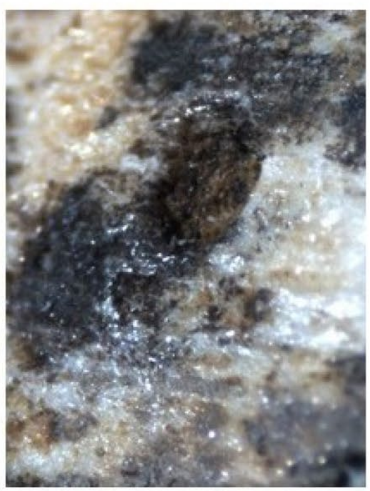

Blackish, not treated

(B_2)

Fig. 6 Optical micrographs of the different laser-treated and non-treated bone areas where laser-induced phenomena and original surface conditions are indicated 
Table 3 Relative surface concentration of elements (atomic \%) detected by XPS on the archaeological bone sample before $(000 \mathrm{~s})$ and after (300 s) $300 \mathrm{~s} \mathrm{Ar}+$ ion etching

\begin{tabular}{llllllllllll}
\hline Sample & Laser & Ca\% & P\% & Si\% & Al\% & S\% & Fe\% & Mn\% & Na\% & N\% & F\% \\
\hline L_W/000 s & Treated & 7.75 & 2.76 & 3.64 & 2.12 & 1.19 & 0.75 & 0.38 & 1.97 & - & 0.49 \\
L_W/300 s & Treated & 8.86 & 2.61 & 3.79 & 2.11 & 1.49 & 0.95 & - & 1.77 & - & 0.35 \\
L_G/000 s & Treated & 5.67 & 2.83 & 5.94 & 3.96 & 0.57 & 1.41 & 0.36 & 1.06 & - & 0.39 \\
L_G/300 s & Treated & 6.74 & 3.35 & 5.96 & 3.98 & - & 1.53 & 0.44 & 1.09 & - & 0.29 \\
Y_1/000 s & Nontreated & 3.72 & 1.75 & 4.14 & 2.11 & - & 0.65 & - & 0.14 & 0.81 & 0.46 \\
Y_1/300 s & Nontreated & 3.89 & 1.58 & 4.38 & 1.89 & - & 0.67 & - & - & 0.45 & - \\
G_1/000 s & Treated & 3.60 & 1.83 & 2.74 & 1.66 & 0.37 & 0.55 & 0.46 & 0.59 & -- & -- \\
G_1/300 s & Treated & 4.40 & 2.17 & 3.16 & 1.84 & - & 0.42 & 0.53 & 0.50 & -- & -- \\
B_1/000 s & Nontreated & 4.93 & 2.85 & 1.51 & 1.19 & 0.18 & 0.28 & -- & - & 0.56 & 0.49 \\
B_1/300 s & Nontreated & 5.49 & 2.99 & 1.78 & 0.84 & 0.32 & 0.50 & 0.39 & -- & -- & -- \\
\hline
\end{tabular}

\section{Conclusions}

This work explored the interaction of an 800 ps (subns) pulsed near IR laser, with emission at 1064 nm, with the contamination and deteriorated layers present in an archaeological Pleistocene bear bone sample of Sierra de Atapuerca, which has undergone severe weathering throughout ages. The laser was operated in burst mode, and laser parameters which avoid damaging the surface of the bone sample were identified. A laser irradiance of $0.20 \mathrm{GW} \mathrm{cm}^{-2}$ was determined as the threshold damage value for these types of samples when working in burst mode. Below this value, the laser irradiation of Pleistocene bone appears safe and may lead the way to efficient and satisfactory cleaning of its surface contaminants. SEM-EDS and XPS characterization studies comparing both, asreceived and laser-irradiated samples, enabled to conclude that contaminants containing mainly mineralogical clay components had been removed from the surface of the bone artefact. The presence of alumino-silicates was mainly found, for example, at its surface and was reduced significantly as the presence of $\mathrm{Ca}$ and $\mathrm{P}$ increased towards the sample's interior and upon laser irradiation. Furthermore, there are no significant compositional changes on the bulk of the archaeological samples during irradiation. Their surface becomes darkened, however, upon laser irradiation above the damage threshold, apparently due to the presence of Fe and Mn within the resolidified surface. These may be present in the artifact for different reasons. Fe compounds may stem from the soil, while Mn could also be originating as a component of the bone itself, as it is particularly found in sufficient content within the sample cross-section and far from its surface.

Acknowledgments Project supported by H2020-MSCA-ITN-EJD/EDARCHMAT action funding under the Marie Skłodowska-Curie grant agreement, no 766311. Partial support obtained from Departamento de Ciencia, Universidad y Sociedad del Conocimiento of Gobierno de Aragón "Construyendo Europa desde Aragón" (research group T54_20R). The Atapuerca research project is financed by Ministerio de Ciencia, Innovación y Universidades project PGC 2018-093925B-C33. Fieldwork at the Atapuerca sites is funded by the Junta de Castilla y León and the Fundación Atapuerca. The fossil analysed in this work was made available by the Laboratory of Human Evolution of the University of Burgos, in close collaboration with the "Colección Museística de Castilla y León" of the Junta de Castilla y León; we acknowledge Professor Juan Luis Arsuaga for the permit to analyse the sample. The use of Servicio General de Apoyo a la Investigación and the National Facility ELECMI ICTS, node "Laboratorio de Microscopías Avanzadas" at the University of Zaragoza is acknowledged. This work is part of the ongoing collaboration between INMA (CSICUniversity of Zaragoza) and University of Burgos, under the auspices of Unidad Asociada de I+D+i al CSIC "Vidrio y Materiales del Patrimonio Cultural (VIMPAC)".

Funding Project funded by H2020-MSCA-ITN-EJD/ED-ARCHMAT action under the Marie Skłodowska-Curie grant agreement, No 766311.

\section{Declarations}

Conflict of interest The authors declare that there is no conflict of interest.

Open Access This article is licensed under a Creative Commons Attribution 4.0 International License, which permits use, sharing, adaptation, distribution and reproduction in any medium or format, as long as you give appropriate credit to the original author(s) and the source, provide a link to the Creative Commons licence, and indicate if changes were made. The images or other third party material in this article are included in the article's Creative Commons licence, unless indicated otherwise in a credit line to the material. If material is not included in the article's Creative Commons licence and your intended use is not permitted by statutory regulation or exceeds the permitted use, you will need to obtain permission directly from the copyright holder. To view a copy of this licence, visit http://creativecommons. org/licenses/by/4.0/.

\section{References}

1. Carbonell E, Bermúdez De Castro JM, Parés JM, Pérez-González A, Cuenca-Bescós G, Ollé A, Mosquera M, Huguet R, Van Der Made J, Rosas A, Sala R, Vallverdú J, García N, Granger DE, Martinón-Torres $M$, Rodríguez XP, Stock GM, Vergès JM, Allué $E$, Burjachs F, Cáceres I, Canals A, Benito A, Díez C, Lozano M, Mateos 
A, Navazo M, Rodríguez J, Rosell J, Arsuaga JL (2008) The first hominin of Europe. Nature 452(7186):465-469. https://doi.org/ 10.1038/nature06815

2. Arsuaga JL, Martínez I, Arnold LJ, Aranburu A, Gracia-Téllez A, Sharp WD, Quam RM, Falguères $C$, Pantoja-Pérez $A$, Bischoff J, Poza-Rey E, Parés JM, Carretero JM, Demuro M, Lorenzo C, Sala N, Martinón-Torres M, García N, Alcázar De Velasco A, Cuenca-Bescós G, Gómez-Olivencia A, Moreno D, Pablos A, Shen CC, Rodríguez L, Ortega Al, García R, Bonmatí A, Bermúdez De Castro JM, Carbonell E (2014) Neandertal roots: cranial and chronological evidence from Sima de los Huesos. Science 344(6190):1358-1363. https://doi.org/10.1126/science.1253958

3. Bermúdez de Castro JM, Martinón-Torres M, Blasco R, Rosell J, Carbonell E (2013) Continuity or discontinuity in the European Early Pleistocene human settlement: the atapuerca evidence. Quat Sci Rev 76:53-65. https://doi.org/10.1016/j.quascirev.2013. 06.023

4. Arnold LJ, Demuro $M$, Navazo $M$, Benito-Calvo A, Pérez-González A (2013) OSL dating of the middle palaeolithic hotel california site, sierra de atapuerca, north-central Spain. Boreas 42(2):285305. https://doi.org/10.1111/j.1502-3885.2012.00262.x

5. Arsuaga JL, Martínez I, Gracia A, Carretero JM, Lorenzo C, García N, Ortega Al (1997) Sima de los Huesos (Sierra de Atapuerca, Spain). The site. J Hum Evol 33(2-3):109-127. https://doi.org/ 10.1006/jhev.1997.0132

6. García N, Arsuaga JL, Torres T (1997) The carnivore remains from the Sima de los Huesos Middle Pleistocene site (Sierra de Atapuerca, Spain). J Hum Evol 33(2-3):155-174. https://doi.org/10. 1006/jhev.1997.0154

7. Hedges REM (2002) Bone diagenesis: An overview of processes. Archaeometry 44(3):319-328. https://doi.org/10.1111/14754754.00064

8. Pfretzschner $\mathrm{H}$ (2004) Fossilization of Haversian bone in aquatic environments. Comptes Rendus Palevol 3:605-616. https://doi. org/10.1016/j.crpv.2004.07.006

9. Florencio-Silva R, Sasso GRDS, Sasso-Cerri E, Simões MJ, Cerri PS (2015) Biology of Bone Tissue: Structure, Function, and Factors That Influence Bone Cells. Biomed Res Int. https://doi.org/10. $1155 / 2015 / 421746$

10. Nicholson RA (1998) Bone degradation in a compost heap. J Archaeol Sci 25(5):393-403. https://doi.org/10.1006/jasc.1997. 0208

11. Higgins IJ, Burns RJ (1975) The chemistry and microbiology of pollution. London Academic Press

12. Middleton W, Barba L, Pecci A, Burton J, Ortiz A, Salvini L, Suárez $R$ (2010) The study of archaeological floors: methodological proposal for the analysis of anthropogenic residues by spot tests, ICP-OES, and GC-MS. J Archaeol Method Theory 17(3):183-208

13. White EM, Hannus LA (1983) Chemical Weathering of Bone in Archaeological Soils. Am Antiq 48(2):316-322. https://doi.org/ $10.2307 / 280453$

14. Bethell $\mathrm{PH}$, Carver $\mathrm{MOH}$ (1987) Detection and enhancement of decayed inhumations at Sutton Hoo. In: Boddington A, Garland AN, Janaway RC (eds) Death, decay and reconstruction: approaches to archaeology and forensic science. Manchester University Press, Manchester, pp 10-21

15. Piepenbrink $H$ (1986) Two examples of biogenous dead bone decomposition and their consequences for taphonomic interpretation. J Archaeol Sci 13(5):417-430. https://doi.org/10.1016/ 0305-4403(86)90012-9

16. Queiroz RA, Soriano EP, Carvalho MVD, Caldas-Junior AF, Souza EHA, Coelho-Junior LGTM, Campello RIC, Almeida AC, Farias RCAP, Vasconcellos A (2016) First forensic records of termite activity on non-fossilized human bones in Brazil. Brazilian J Biol 77(1):127-131. https://doi.org/10.1590/1519-6984.11415
17. Jans $M M E$, Kars $H$, Nielsen-Marsh $C M$, Smith $\mathrm{Cl}$, Nord $A G$, Arthur P, Earl N (2002) In situ preservation of archaeological bone: a histological study within a multidisciplinary approach. Archaeometry 44(3):343-352. https://doi.org/10.1111/14754754.t01-1-00067

18. Cooper M (1998) Laser cleaning in conservation : an introduction. Butterworth-Heinemann, UK

19. Szmygin B (2016) Protection of historic monuments and sites - achievements, problems, perspectives. In: Szmygin B (ed) Heritage for Future 1(3). Heritage in Transformation: cultural heritage protection in XXI century - problems, challenges, predictions; ICOMOS International Scientific Committee for Theory and Philosophy of Conservation and Restoration, Lublin, Poland, pp 191-200

20. Siano S (2007) Principles of laser cleaning in conservation. In: Handbook on the use of lasers in conservation and conservation science. COST G7 7 1-26

21. Gemeda BT, Lahoz R, Caldeira AT, Schiavon N (2018) Efficacy of laser cleaning in the removal of biological patina on the volcanic scoria of the rock-hewn churches of Lalibela, Ethiopia. Environ Earth Sci 77(2):1-12. https://doi.org/10.1007/s12665-017-7223-3

22. Pouli P, Oujja M, Castillejo M (2012) Practical issues in laser cleaning of stone and painted artefacts: optimisation procedures and side effects. Appl Phys A Mater Sci Process 106(2):447-464. https://doi.org/10.1007/s00339-011-6696-2

23. Asmus JF, Murphy CG, Munk WH (1973) Studies on the interaction of laser radiation with art artifacts. Dev laser Technol II no Proc SPIE 41:19-30

24. Lazzarini L, Marchesini L, Asmus JF (1973) Lasers for the cleaning of statuary: initial results and potentialities. J Vac Sci Technol 10(6):1039-1043. https://doi.org/10.1116/1.1318462

25. Siano S, Giamello M, Bartoli L, Mencaglia A, Parfenov V, Salimbeni $R$ (2008) Laser cleaning of stone by different laser pulse duration and wavelength. Laser Phys 18(1):27-36. https://doi. org/10.1134/S1054660X08010064

26. Asmus JF, Parfenov VA, Elford JP (2017) Final Endeavors of 'Monument Man'. 15-24. https://doi.org/10.12775/3875-4.01

27. Asmus JF (1986) More light for art conservation. IEEE Circuits Devices Mag 2:6-14

28. Lahoz R, Angurel LA, Brauch U, Estepa LC, de la Fuente Leis GF (2013) Laser applications in the preservation of cultural heritage: an overview of fundamentals and applications of lasers in the preservation of cultural heritage. In: Varella EA (ed) Conservation science for the cultural heritage: applications of instrumental analysis, pp 294-332. https://doi.org/10.1007/ 978-3-642-30985-4

29. Bromblet $P$, Labouré $M$, Orial G (2003) Diversity of the cleaning procedures including laser for the restoration of carved portals in France over the last 10 years. J Cult Herit 4(SUPPL. 1):17-26

30. Bilmes GM, Freisztav C, Schinca D, Orsetti A (2005) Cleaning and characterization of objects of cultural value by laser ablation. Opt Methods Arts Archaeol 5857(1900):585704. https://doi.org/ 10.1117/12.612671

31. Marczak J, Koss A, Targowski P, Góra M, Strzelec M, Sarzyński A, Skrzeczanowski W, Ostrowski R, Rycyk A (2008) Characterization of laser cleaning of artworks. Sensors (Switzerland) 8(10):65076548. https://doi.org/10.3390/s8106507

32. Al Sekhaneh W, El Serogy A, El-Bakri M (2015) Yag-laser cleaning of archaeological materials in Jordanian museums. Mediterr Archaeol Archaeom 15(3):157-164. https://doi.org/10.5281/ zenodo.19297

33. Andreotti A, Colombini MP, Nevin A, Melessanaki K, Pouli P, Fotakis C (2006) Multianalytical study of laser pulse duration effects in the IR laser cleaning of wall paintings from the monumental cemetery of Pisa. Laser Chem 2006:1-11. https://doi.org/10. $1155 / 2006 / 39046$ 
34. Di Niso F, Gaudiuso C, Sibillano T, Mezzapesa FP, Ancona A, Lugarà PM (2014) Role of heat accumulation on the incubation effect in multi-shot laser ablation of stainless steel at high repetition rates. Opt Express 22(10):12200. https://doi.org/10.1364/ oe. 22.012200

35. Gaudiuso C, Giannuzzi G, Volpe A, Lugarà PM, Choquet I, Ancona A (2018) Incubation during laser ablation with bursts of femtosecond pulses with picosecond delays. Opt Express 26(4):3801. https://doi.org/10.1364/oe.26.003801

36. Arenberg J (1990) A set of standard definitions for laser damage parameters and procedures. In: Bennett $H$, Chase L, Guenther A, Newnam B, Soileau M (eds) Laser induced damage in optical materials: 1989. ASTM International, West Conshohocken, PA, pp 9-9. https://doi.org/10.1520/STP26470S

37. Besozzi E, Maffini A, Dellasega D, Russo V, Facibeni A, Pazzaglia A, Beghi MG, Passoni M (2018) Nanosecond laser pulses for mimicking thermal effects on nanostructured tungsten-based materials. Nucl Fusion 58(3):036019. https://doi.org/10.1088/ 1741-4326/aaa5d5

38. Aranburu A, Arsuaga JL, Sala N (2017) The stratigraphy of the Sima de los Huesos (Atapuerca, Spain) and implications for the origin of the fossil hominin accumulation. Quat Int 433:5-21. https://doi.org/10.1016/j.quaint.2015.02.044

39. Bischoff JL, Fitzpatrick JA, León L, Arsuaga JL, Falgueres C, Bahain $J J$, Bullen T (1997) Geology and preliminary dating of the hominid-bearing sedimentary fill of the Sima de los Huesos Chamber, Cueva Mayor of the Sierra de Atapuerca, Burgos, Spain. J Hum Evol 33(2-3):129-154. https://doi.org/10.1006/jhev.1997.0130

40. Suarez CA, Morschhauser EM, Suarez MB, You H, Li D, Dodson $P$ (2018) Rare earth element geochemistry of bone beds from the lower cretaceous zhonggou formation of Gansu Province, China. J Vertebr Paleontol 38(sup1):22-35. https://doi.org/10. 1080/02724634.2017.1400441

41. Liu JM (1982) Simple technique for measurements of pulsed Gaussian-beam spot sizes. Opt Lett 7(5):196-198

42. Schaaf $P(2010)$ Laser processing of Materials: fundamentals, applications and developments, Springer series in materials science, Springer science \& business media, ISBN 32812, 9783642132810, vol 139, Chap 3

43. Kannatey-Asibu E (2009) Principles of laser materials processing, Wiley, ISBN 978-0-470-17798-3, Chap 14

44. Rubahn H-G (1999) Laser applications in surface science and technology

45. Salimbeni R (2006) Laser techniques for conservation of artworks. Archeometriai Mühelly 1:34-40
46. Emmelmann C, Pablo J, Urbina C (2011) Analysis of the influence of burst-mode laser ablation by modern quality tools. Phys Procedia 12:172-181. https://doi.org/10.1016/j.phpro.2011.03.119

47. Lahoz R, De La Fuente GF, Pedra JM, Carda JB (2011) Laser engraving of ceramic tiles. Int J Appl Ceram Technol 8(5):12081217. https://doi.org/10.1111/j.1744-7402.2010.02566.x

48. Yakovlev E, Shandybina G, Shamova A (2019) Modelling of the heat accumulation process during short and ultrashort pulsed laser irradiation of bone tissue. Biomed Opt Express 10:3030-3040

49. Di Francia E, Angurel LA, Angelini E, Grassini S, Lahoz R, Parvis $M$ (2016) Laser cleaning of archaeological bronze artefacts. Eur Corros Congr EUROCORR 2:1031-1039

50. Rey-García F, Gutiérrez-Mora F, Borrel CJ, Estepa LC, Angurel LA, De La Fuente GF (2018) Microstructural characterization and tribological behavior of Laser Furnace processed ceramic tiles. Ceram Int 44(6):6997-7005. https://doi.org/10.1016/j.ceramint. 2018.01.133

51. Cheng GJ, Pirzada D, Cai M, Mohanty P, Bandyopadhyay A (2005) Materials Science and Engineering, C 25:541-547

52. Della Pepa G, Brandi ML (2016) Microelements for bone boost: the last but not the least. Clin Cases Miner Bone Metab 13(3):181-185. https://doi.org/10.11138/ccmbm/2016.13.3.181

53. Wopenka B, Pasteris JD (2005) A mineralogical perspective on the apatite in bone. Mater Sci Eng C 25(2):131-143. https://doi. org/10.1016/j.msec.2005.01.008

54. Kohn MJ, Cerling TE (2019) Stable isotope compositions of biological apatite. Phosphates Geochem Geobiol Mater Import McCrea 1950 48:455-488. https://doi.org/10.2138/rmg.2002. 48.12

55. Trueman CN, Tuross N (2019) Trace elements in recent and fossil bone apatite. Phosphates Geochem, Geobiol Mater Importance 48:489-522. https://doi.org/10.2138/rmg.2002.48.13

56. Gutiérrez AM, Ruiz MM, Barredo FJ (2017) Estudio experimental acerca de la pátina que adquieren los materiales de sílex neógeno procedente de la sierra de Atapuerca," Arqueol. en el Val. del Duero Del Paleolítico a la Edad Media. 5, pp 35-52

57. Deng Y, Zhou Y, Yang Y, Shi X, Zhang K, Zhang P, Yang W (2018) Preparation and coloration of colored ceramics derived from the vanadium-titanium slags. Adv Mater Sci Eng. https://doi.org/10. $1155 / 2018 / 5085031$

Publisher's Note Springer Nature remains neutral with regard to jurisdictional claims in published maps and institutional affiliations. 